\title{
Incorporating Stigma Into Implementation Science: Linking Societal Influence to the Clinical Encounter to Understand Inequities in Healthcare Delivery
}

M. Elle Saine ( $\nabla$ msaine@pennmedicine.upenn.edu )

University of Pennsylvania Perelman School of Medicine https://orcid.org/0000-0002-1037-5610

Vincent Lo Re, III

University of Pennsylvania Perelman School of Medicine

Frances K. Barg

University of Pennsylvania Perelman School of Medicine

Julia E. Szymczak

University of Pennsylvania Perelman School of Medicine

\section{Research}

Keywords: hepatitis C virus, stigma, Health Equity Implementation Framework, intersectionality, mixed methods, healthcare disparities

Posted Date: July 28th, 2020

DOl: https://doi.org/10.21203/rs.3.rs-47724/v1

License: (9) This work is licensed under a Creative Commons Attribution 4.0 International License. Read Full License 


\section{Abstract}

Background: Disease-related stigma is an important, but under recognized barrier to the implementation of evidence-based therapies. Existing implementation science frameworks do not adequately specify the mechanisms by which the outer societal context produces disparate implementation outcomes. Our aim in this study was to evaluate how stigma influences the implementation of evidence-based hepatitis $\mathrm{C}$ virus (HCV) care and, in so doing, make the case for incorporating stigma into the Health Equity Implementation Framework.

Methods: From 2015-2019, we conducted a concurrent explanatory mixed-methods study among people living with HCV in Philadelphia. We administered the validated 33-item HCV-stigma scale. Semi-structured interviews were conducted among a purposive subsample of survey respondents. Summative HCVstigma scale scores and descriptive statistics were calculated. Interviews were transcribed and analyzed for common themes. Survey responses were linked to interview data.

Results: Surveys were completed by 265 participants; 22 interviews were conducted with a subset of these respondents. Hispanic/Latinx ethnicity was associated with significantly higher HCV-stigma scale scores (adjusted mean, 81.39 [95\% Cl, 76.44-86.33] versus 74.28 [95\% $\mathrm{Cl}, 70.51-78.05]$; $P=0.025$ ). In interviews, participants described the impact of stigma on their engagement with HCV care. Stigma associated with their diagnosis contributed to feelings of dirtiness and shame. Participants described the critical importance of interactions with medical providers and the healthcare system as a whole to either facilitating or mitigating the negative impact of enacted stigma on their trust in medicine and willingness to engage with HCV care. Interactions with family and friends, especially surrounding disclosure of one's diagnosis, were an important mediator of the experience of stigma. Hispanic/Latinx participants described greater feelings of isolation and stigma from family and friends as a result of their diagnosis. Finally, participants described the way stigma shaped their and society's perceptions of HCV therapies, including the media portrayal of pharmaceuticals, the high cost of drugs and insurer denials of treatment.

Conclusions: Experiences of HCV-related stigma influence engagement with HCV care at multiple levels: patient, provider, family and community, and perceptions of the therapy itself. Incorporating stigma into the Health Equity Implementation Framework can improve the utility of the framework by specifying a mechanism by which the social context influences the uptake of evidence-based innovations.

\section{Contributions To The Literature}

- We examine the way stigma impacts patient engagement with curative therapies for hepatitis $\mathrm{C}$ virus (HCV).

- We demonstrate that HCV-related stigma influences engagement with healthcare at multiple levels: patient, provider, family and community, and perceptions of the therapy itself.

- Through this case we propose a modification of the Health Equity Implementation Framework to incorporate stigma as a mechanism by which the social context impacts the implementation of 
evidence-based innovations.

- These findings address noted gaps in previous literature, by investigating the social relations that produce stigma experiences and the way stigma impacts implementation, contributing to disparities in access to evidence-based care.

\section{Background}

Implementation science has the potential to substantially improve population health by establishing and evaluating strategies to increase uptake of evidence-based interventions to prevent and cure disease (13). However, the population-level effectiveness of implementation science is restricted by frameworks that do not account for the role of healthcare disparities on the equitable delivery of interventions $(2,4)$. Implementation strategies that do not account for health disparities have the potential to widen inequalities and further marginalize vulnerable patients $(2,4,5)$. Integrating theory, methods, and measures that account for health disparities within implementation science frameworks can promote the equitable distribution of evidence-based innovations that improve health.

\section{The Health Equity Implementation Framework}

The recently proposed Health Equity Implementation Framework (4) combines conceptual frameworks from implementation science and healthcare disparities research to better integrate health equity determinants into research on the factors that shape the uptake of evidence-based innovations (Fig. 1a). Central in the framework is the clinical encounter, which is conceptualized as a site of interaction between an innovation and its intended recipients, including the patient, clinician, and others involved in the delivery or receipt of the innovation (e.g. peer educator, family member). A novel contribution of the Health Equity Implementation Framework is its explicit integration of sociopolitical and economic influences on the context in which innovations are delivered. While existing determinant frameworks in implementation science include some reference to the broader social world in which innovations are enacted (the "outer setting"), the mechanisms by which societal factors produce implementation outcomes are often underspecified.

Frameworks in implementation science deliver value to the field by unifying inconsistent terminology across theories to provide common definitions of phenomena and foundations for measurement $(1,6,7)$. To bolster the utility of the Health Equity Implementation Framework in advancing our understanding of how health equity determinants shape implementation outcomes, we suggest explicit incorporation of an additional theoretical construct: stigma. Stigma is defined as a "deeply discrediting attribute" that differs from socially-defined "normal" attributes (8). Stigmatized attributes include disease/illness, behaviors, and social identities, including race and ethnicity (8). The consequences of stigma on worsening health outcomes and health disparities are well established $(3,9,10)$. When multiple stigmatized identities intersect, experiences of stigma, social exclusion, and marginalization are intensified. Intersectional stigmas reinforce disparities in healthcare by impacting delivery of service and erecting barriers to disease understanding and treatment, potentially altering the course of illness (11-14). 
In this manuscript we present a case study that demonstrates how disease-related stigma shapes the implementation of an evidence-based clinical innovation. We argue that stigma is an important mechanism connecting societal influences to the clinical encounter in the Health Equity Implementation Framework. By increasing the specificity regarding how social and structural influences impact recipients and characteristics of the innovation, we can incorporate methods and measures specific to health disparities to improve our understanding of the way that social factors influence implementation.

\section{The Case: Hepatitis C virus Infection and Stigma}

Hepatitis $\mathrm{C}$ virus (HCV) is a leading cause of liver-related morbidity and infectious disease mortality (1517). In 2014, all-oral direct acting antiviral (DAA) therapies were approved for the treatment of HCV. DAA regimens are highly efficacious and effective with 8-24 weeks of therapy, with low side-effect profiles, and high cure rates $(\geq 95 \%$ SVR) (18-21). Curative treatment of HCV infections decreases HCV-related morbidity and mortality, liver disease progression, and end-stage complications, while prolonging survival, decreasing transmission, and improving health-related quality of life (22-26). However, only a minority of patients receive the health benefits of these evidence-based therapies, with treatment uptake averaging less than $15 \%(18,27-33)$. Multiple studies demonstrate lower rates of DAA therapy initiation among Black/African American and Hispanic/Latinx patients (34-37). Disparities in receipt of treatment increase HCV-related morbidity and mortality for affected patients, limit the population-level effectiveness of DAA therapies, and slow progress towards HCV elimination (38). HCV-related stigma has been found to decrease testing; erect barriers to disease understanding and treatment; and encourage social avoidance, isolation, and withdrawal (11-14).

Through the use of an intersectionality framework, we can better understand how the individual microlevel experiences of disease-related stigmas are shaped by macro-level social inequalities, such as racism (39-45). Intersectionality frameworks depart from previous public health frameworks that independently evaluate systems of privilege and oppression as individual processes, by recognizing that multiple structural systems interlock in ways that promote advantage and disadvantage at social and individual levels. $(45,46)$ Stigma is inherently rooted in systems of social, economic, and political power and control, and intersectional stigmas manifest within matrices of structural inequalities.(47, 48) We applied an intersectionality framework to the developed questions and analyses a priori to elucidate how structural marginalization and social stigma impact health experiences and stigma associated with HCV.(48-50) In this study, we use a mixed-methods approach to assess how intersectional stigmas, including the intersection of racism with HCV-related stigma, impacts the implementation of evidence-based DAA therapies. Based on the findings of this analysis we propose that the Health Equity Implementation Framework be modified to include stigma as a factor that specifies a mechanism by which societal influence shapes the clinical encounter.

\section{Methods}

\section{Study Design \& Setting}


We conducted a concurrent explanatory mixed-methods study among patients with a history of HCV infection who presented for care at outpatient infectious diseases clinics across Philadelphia, Pennsylvania. Participants were recruited from five clinics across two health systems between July 2018 and May 2019: 1) University of Pennsylvania Health System; (Center for Viral Hepatitis at Penn Presbyterian Medical Center; Hospital of the University of Pennsylvania MacGregor Infectious Diseases Clinic) and, 2) Philadelphia Field Initiation Group for human immunodeficiency virus (HIV) Trials (FIGHT) Community Health Centers (Jonathan Lax Treatment Center; John Bell Health Center; Clinica Bienestar). The clinics offer comparable HCV treatments and the demographic characteristics of the patient populations are representative of chronic HCV-infected patients in Philadelphia.(51-53) Methods are reported in accordance with COREQ (Consolidated Criteria for Reporting Qualitative Research) guidelines (54). This study was approved by the Institutional Review Boards of the University of Pennsylvania (Protocol, 829550) and Philadelphia FIGHT.

\section{Participants \& Recruitment}

Eligible participants were: 1) $\geq 18$ years old; 2) HCV-antibody positive, including those with chronic infection, spontaneously cleared HCV infection, or cured with antiviral treatment; and 3) English-speaking. The study team was led by MES, a female PhD student in Epidemiology with a master's degree in anthropology, who collected all data as part of her dissertation research. She was supervised by JES \& FKB, female social scientists with expertise in mixed-methodology and VLR, an infectious diseases physician with expertise in epidemiology. MES attended each clinic during the times when providers who treat mostly people living with HCV were providing care and approached potential participants for enrollment at the end of their outpatient appointment. Participants were recruited in person by the principal investigator, whom they did not know prior to study commencement. The goal of the study, to understand how stigma impacts the experiences of people living with HCV, was made clear to participants at the time of recruitment.

For survey data, 248 participants were deemed sufficient to achieve $80 \%$ power to detect associations between HCV-related stigma and hypothesized risk factors. For linked semi-structured interviews, we recruited a subsample of participants who completed the survey using purposive sampling aimed at maximizing variation with regards to race, sex, and gender. Interview recruitment continued until thematic saturation was achieved, whereby further data collection yielded no new or relevant information $(55,56)$.

\section{Data Collection}

Surveys were administered on laptop computers equipped with headphones using audio-computer assisted self-interview (ACASI) software, a user-friendly digital data collection interface, using audiorecorded instructions, questions, and answers to guide participants through a survey (57). Survey data included self-reported patient demographics (age, sex/gender, race, ethnicity, education), history of injection drug use, sexual orientation, HIV infection status, years since HCV diagnosis, and stage of HCV management (i.e., spontaneously cleared; diagnosed, untreated; previously treated, not cured; currently being treated; treated, cured). All participants completed the HCV Stigma Scale (HCV-SS), a previously- 
validated (construct validity, 85\%) and reliable (Cronbach a, 0.96) self-administered 33-item questionnaire (58) adapted from the Berger HIV Stigma Scale (59). Questions address domains of personalized stigma, negative self-image, disclosure of infection, and public attitudes, with responses recorded on a four-point Likert scale (1 [strongly disagree] to 4 [strongly agree]). The total HCV-SS score is summed from item scores (range, 33-132), with higher scores indicating greater experiences of stigma.

Qualitative data were collected via an open-ended free-response question within the survey instrument and in-depth semi-structured interviews among a subset of participants. To contextualize situations within which perceptions of HCV-related stigma arise and influence engagement with healthcare, our interview guide contained four thematic domains: 1) individual perceptions of HCV infection; 2) medical knowledge about HCV infection; 3) social support and interpersonal interactions; and, 4) healthcare interactions. Sub-questions and probes encouraged respondents to reflect on actual interactions or situations. All interview questions were designed to be open-ended and non-leading; participants were encouraged to share stories and experiences that were most important to them.

All interviews were audio-recorded, with the permission of the respondent. The Interviewer took notes by hand and wrote memos following each interview. Audio-recordings were transcribed by a third-party Health Insurance Portability and Accountability Act of 1996 (HIPAA)-certified transcription service. Interview transcripts and survey free-response data were uploaded to NVivo 11 qualitative data analysis software (QSR International, Melbourne, Australia, 2015) and linked to survey data. Data were analyzed using a combination of inductive theme generation, $(60,61)$ the application of an intersectionality framework to coded data $(62,63)$ and, for the purposes of the analysis presented in this manuscript, organization of our findings using the Health Equity Implementation Framework. All codes were evaluated for meta-themes, thematic variation, and relationships among codes (MES coded all qualitative data, JES \& FKB reviewed codebooks, themes, and analyses) (64).

\section{Statistics}

Baseline descriptive statistics were calculated as counts and proportions. Some response categories were collapsed in reported data to limit small cell counts. Difference in characteristics between participants with and without interview and/or free-response data were assessed using chi-square or Fisher's exact tests, as indicated, for categorical variables and $t$ tests for continuous variables. Mean HCV stigma scale scores were calculated overall and by race/ethnicity. Due to the low number of HCV-monoinfected participants participating in interviews, we did not stratify analyses by HIV status. All quantitative analyses were conducting using Stata 15.0 (Stata Corporation, College Station, TX).

\section{Results}

\section{Participant Characteristics}

We approached 288 patients for the survey study, of whom 270 (96.4\%) agreed to participate, and 265/270 (98.1\%) completed the entire survey. Qualitative data (interviews and/or free-response survey 
item) were collected for 96 participants (36.2\%), of whom, $84(31.7 \%)$ provided survey free-response data and 22 (8.3\%) participated in in-depth interviews. Each interview lasted approximately 45 to 60 minutes. There was no difference in baseline characteristics between those who chose to contribute qualitative data (interview and/or free-response) and those with quantitative data only. However, compared to those who were not interviewed, interviewees were more likely to be coinfected with HIV $(P=0.002)$ and diagnosed within the previous five years $(P=0.016)$. The likelihood of contributing qualitative data $(P=$ 0.896) or interview participation $(P=0.483)$ did not differ by HCV-SS score (Table 1 ).

\section{HCV-SS Scores}

Hispanic/Latinx participants had significantly higher HCV-SS scores compared to White, non-Hispanic participants (adjusted mean, 81.39 [95\% Cl, 76.44-86.33] versus 74.28 [95\% $\mathrm{Cl}, 70.51-78.05] ; \mathrm{P}=0.025$ ). Compared to White, non-Hispanic participants, mean stigma scores were similar for Black/African American, non-Hispanic participants (adjusted mean, 74.33 [95\% Cl, 70.54-78.12]; $\mathrm{P}=0.984$ ) and participants who did not identify as White, Black/African American, or Hispanic/Latinx ("Other"; adjusted mean, 69.08 [95\% Cl, 58.72-79.43]; $\mathrm{P}=0.354$ ). Between $84.6 \%$ and $98.3 \%$ endorsed at least one question indicating experiences of HCV-related stigma; endorsement of stigma experiences did not differ by race/ethnicity (Table 2).

\section{Experiences of HCV-related Stigma}

Qualitative analyses revealed the influence of stigma within the clinical encounter, as well as downstream societal experiences. Subtheme analyses identified how stigma within the clinical encounter may impact engagement with care and uptake of DAA therapies. Table 3 summarizes these subthemes and presents exemplar quotes.

\section{Patient Factors}

Many patients described feelings of internalized stigma (inward negative feelings or self-image), with salient subthemes including feeling unclean and shame. Of note, all participants who described feeling unclean reported a history of injection drug use, describing how their internalized feelings of dirtiness related to HCV intersected with feelings of dirtiness associated with use of injection drugs. Some patients elaborated a fear that the sense of dirtiness due to HCV infection would persist following cure.

Many patients described feelings of guilt and shame regarding their HCV diagnosis; some further contextualized this within shame of infection through injection drug, describing HCV as a symbol of their drug use history, in addition to a disease. Multiple participants expressed concerns that disclosing their HCV status would reveal their history of drug use. Alternatively, patients who explicitly described not feeling ashamed also contextualized this within discussion of transmission, with some directly stating that they did not contract HCV through drug use or the mode through which they were infected (e.g. blood transfusion).

\section{Provider Factors}


Patients widely described supportive healthcare environments as an important facilitator of engagement with care and treatment. Multiple participants described their HCV-providers as sources of emotional support who eased experiences of HCV-related stigma.

While participants overwhelmingly reported positive experiences with their HCV-care providers, the juxtaposition of negative experiences with HCV stigma in other healthcare settings underpinned the importance of a supportive treatment environment. Negative healthcare experiences were reported within clinical encounters where patients were seeking HCV treatment, as well as in other non-specialty healthcare settings, including the Emergency Department. Healthcare stigma ranged from perceptions of differential treatment to direct refusal of care. For many patients, experiences of HCV stigma in healthcare posed significant barriers to linkage with specialty care.

Multiple participants who identified as Black/African American recounted experiences of racism in healthcare, including how provider-level racial biases and structural racism in medicine impacted engagement in HCV care. Moreover, Black/African American patients more frequently discussed the importance of trust in providers, and how mistrust of healthcare is an important barrier to care. Alternatively, Hispanic/Latinx participants who were born outside of the US specifically described their healthcare providers as their sole source of social support.

\section{Interpersonal Relationships}

Support from friends and family emerged as an important facilitator of engagement with care and motivator of treatment. Perceived HCV-related stigma reduced participants' willingness to disclose their HCV status and seek out social and emotional support. Almost all participants who described positive disclosure experiences had HCV-SS scores below the mean.

White participants more often endorsed that they had not been treated differently by friends or family following their HCV diagnosis, while Hispanic/Latinx and black/African American participants more frequently described experiences of shaming, social distancing, and negative disclosure experiences. Moreover, Hispanic/Latinx participants frequently described familial experiences of HCV-related stigma intersecting with stigmas towards injection drug use. HCV-related stigma from family regularly led to internalized feelings of shame and decreased self-worth. Furthermore, the extent of social support that participants received outside of healthcare impacted both their willingness to seek care, as well as their reliance on healthcare as a source of social support.

\section{Characteristics of DAA Therapies}

Across analyses, participants described the costs of DAAs and insurer restrictions on treatment as a barrier to care that illustrated societal stigmas towards HCV. Moreover, participants frequently discussed how the intersection of HCV and injection drug use stigma impacts treatment delivery. For many participants, the high cost of DAA therapies fosters distrust in the healthcare system as a business that differentially cares about the health of its consumers. Insurer-denial of therapies reinforces this distrust and the stigma experienced by patients, and itself is a barrier to continued engagement with healthcare. 
Black/African American participants more frequently discussed the power of the media to facilitate HCV care and reduce stigma. Specifically, participants explained how advertisements for DAA therapies raise awareness of HCV and the curability of the disease. Alternatively, representations that normalized HCV, such as diverse portrayals of patients, dispelled some of the myths and stigmas that intersect on HCV.

\section{Discussion}

Using a mixed-methods approach, we evaluated the influence of HCV-related stigma in the DAA treatment era. We found that most patients experience some degree of stigma related to their HCV diagnosis. While the likelihood of experiencing HCV-related stigma did not vary by race/ethnicity, Hispanic/Latinx participants had significantly higher HCV-SS scores than their White counterparts. In our qualitative analyses, we found that among Hispanic/Latinx patients, social rejection and isolation due to HCVrelated stigma may be heightened, ultimately reinforcing internalized stigmas. Our findings demonstrated the important impact of HCV-related stigma within the clinical context at the level of self, the provider, friends and family, and perceptions of DAA therapies. HCV stigma within the clinical setting was an important barrier to care and access to DAA therapies. Additionally, participants described experiences of differential treatment due to both HCV status and race. Specifically, we found that Black/African American participants more frequently described experiences of racism in healthcare.

Taken together, our findings suggest race and racism intersect upon patients' experiences of HCV-related stigma, shaping experiences with HCV and access to evidence-based curative therapies. Our finding that many patients with HCV experienced stigma in healthcare is consistent with pre-DAA era research, which reported that patients with HCV often experience both overt and subtle refusal of care across clinical settings (65-68). Further, Black/ African American patients more frequently described discrimination and mistrust of providers, illustrating how racism in healthcare may intersect with HCV-related stigma. Treloar et al. (2013) identified patients' mistrust in providers as essential barriers at multiple stages of HCV care, including engagement with healthcare, uptake and adherence to treatment, and behavioral changes (69). Similar to previous research (70), we found that among patients with HCV who are highly stigmatized in healthcare, compassionate treatment by a provider is seen as exceptional, rather than expected. Alternatively, previous studies among patients with HCV found that building trust with physicians can help counter other experiences of stigma and promote positive behavioral change $(69,71)$. We also found that positive experiences in healthcare lessen the burden of HCV-related stigma among patients, and patients who have been shunned by friends and family increasingly relied on healthcare as an important source of social support.

We found that stigma associated with DAA therapies, specifically insurer and economic restrictions on access to treatment, reinforced perceptions of HCV-related stigma in healthcare. Societally, the high cost of DAAs has been associated with insurer treatment restrictions and reimbursement denial, effectively rationing curative therapies $(28,29,72,73)$. Criteria for reimbursement vary across insurers and statebased Medicaid programs, often requiring evidence of advanced liver fibrosis and/or abstinence from alcohol or illicit drugs $(28,74,75)$, which is inconsistent with current treatment guidelines $(18,27)$. 
Participants perceived restrictions of DAA therapy as symbolic of HCV stigma in society and healthcare. Our study adds to a growing body of literature that demonstrates the multiple levels of influence at which HCV stigma and perceptions of differential treatment can further marginalize already vulnerable patient populations and be a significant barrier in the implementation of evidence-based treatment (66).

Stigmas are socially-produced and maintained through differential access to power and social inclusion (76). The downstream influences of stigma on recipients and the innovation can produce disparate outcomes; when disease-related stigmas intersect with other experiences of stigma, such as racism or injection drug use stigma, the effect may become compounded. Woodward et al (4) argue that attention to the clinical encounter is particularly important in health equity frameworks, as the unique interactions within the clinical setting can have important implications for whether an evidence-based intervention is delivered. They argue that implementation science should measure societal influences that have downstream impacts on the delivery of an intervention, particularly as they impact disparities in healthcare. Our findings add to this by demonstrating the important role of stigma as a vehicle through which social factors impact the clinical encounter. Experiences of intersectional stigma in healthcare map on to the levels of the Health Equity Implementation Framework in a way that allows us to evaluate how societal influences shape the clinical encounter, and ultimately, implementation success (Fig. 1b).

Frameworks are useful because they encourage the shared use of rigorous methods utilizing validated measures to advance implementation science research (77). Recognizing that stigma may be operationalized differently across levels of the model is necessary. While stigma may arise from the outer societal influence, it is not relegated to this layer, and may penetrate deeper to directly incorporate into a patient's sense of self and impact interactions with others. Therefore, measures that assess stigma at the level of the self, provider, social circle, and innovation will allow us to measure stigma as a barrier to implementation in order to better understand how inequalities may shape delivery of evidence-based innovations.

A central aim of implementation science, is developing generalizable knowledge that can be widely applied beyond individually studied systems (1). We believe that the incorporation of intersectional stigma into the Health Equity Implementation Framework (4) has utility beyond the study of HCV. Intersectional stigmas reinforce disparities in healthcare through the profiling of patients with substance abuse, emotional problems, and lower education as "difficult" and subsequent treatment of these patients as vectors of disease, criminals, or undeserving of health and social participation $(43,78-80)$. The stigmatizing label of a disease and associated assumptions about patients can dissuade medical engagement, impact delivery of service, and alter the course of illness (11-14); investigation of intersectional stigma provides insights into why patients with the same disease may experience stigma differently (42). Research that contributes to our understanding of the role that social factors, such as disease-related stigma, play in the uptake of evidence-based practices can be applied beyond individual systems of study. 
This study has some limitations. As with all qualitative research, the amount and depth of information provided by participants depended on interactions with the interviewer, interview environment, and the subject's motivation for participating in the interview. Participant recall of past experiences may not reflect how they felt at that time, but rather be informed by their current perceptions associated with their illness identity. Finally, we only assessed stigma at the level of the patient. More research, including development of validated measures, is needed to better understand bidirectional stigmas between participants.

\section{Conclusions}

In conclusion, we found that disease-related stigma among patients with HCV intersects with other significant health disparities factors in ways that can hamper the equitable uptake of curative therapy. By incorporating intersectional stigma into the Health Equity Implementation Framework, future implementation studies may be able to better elucidate social influences that promote health disparities and impact delivery of evidence-based innovations.

\section{Declarations}

\section{Ethics approval and consent to participate}

This study was approved by the Institutional Review Boards of the University of Pennsylvania (Protocol, 829550) and Philadelphia FIGHT

\section{Consent for publication}

All participants provided verbal informed consent before participating in the study, which included consent to publish anonymous quotes from individual participants.

\section{Availability of data and materials}

The data are not publicly available because (1) they contain sensitive, identifiable protected health information and (2) research participants did not consent to public release of their data. De-identified data may be made available to qualified researchers by request of the corresponding author, the University of Pennsylvania Office of Research Services (ORSMTA@pobox.upenn.edu), and the University of Pennsylvania Institutional Review Board (irb@pobox.upenn.edu). Requests will be considered on an case-by-case basis. If approved, researchers must submit a Material Transfer Agreement to the corresponding author and University of Pennsylvania Office of Research Services. Additionally, research proposals must have an institutional review board-approved research protocol from their home institution.

\section{Competing interests}

The authors declare that they have no competing interests. 


\section{Funding}

Research reported in this publication was supported by a 2018 Pilot Grant from the Leonard Davis Institute of Health Economics Research at the University of Pennsylvania (to MES) for the development and implementation of this study; the National Institute of Allergy and Infectious Diseases (R01-Al136626; to VLR); and the National Institute on Aging (5T32AG051090-04). The funders had no role in study design, data collection and analysis, decision to publish, or preparation of the manuscript.

\section{Authors' contributions}

MES, VLR, FKB, and JES contributed to the study conception and design. Data collection and analyses were performed by MES. VLR provided clinical expertise and expertise in quantitative data analysis and interpretation; JES and FKB provided expertise in qualitative data analysis and interpretation. The first draft of the manuscript was written by MES and JES; all authors commented on previous versions of the manuscript. All authors read and approved the final manuscript.

\section{Acknowledgements}

The authors would like to thank the providers and staff at the participating clinical sites for their support of this study.

\section{Abbreviations}

ACASI: audio-computer assisted self-interview

COREQ: Consolidated Criteria for Reporting Qualitative Research

DAA: direct acting antiviral

FIGHT: Field Initiation Group for HIV Trials

HCV: hepatitis C virus

HCV-SS: HCV Stigma Scale

HIPPA: Health Insurance Portability and Accountability Act

HIV: human immunodeficiency virus

\section{References}

1. Bauer MS, Damschroder L, Hagedorn H, Smith J, Kilbourne AM. An introduction to implementation science for the non-specialist. BMC Psychol. 2015;3:32. 
2. Chinman M, Woodward EN, Curran GM, Hausmann LRM. Harnessing Implementation Science to Increase the Impact of Health Equity Research. Med Care. 2017;55(Suppl 9 Suppl 2):16-s23.

3. Kemp CG, Jarrett BA, Kwon C-S, Song L, Jetté N, Sapag JC, et al. Implementation science and stigma reduction interventions in low- and middle-income countries: a systematic review. BMC Med. 2019;17(1):6.

4. Woodward EN, Matthieu MM, Uchendu US, Rogal S, Kirchner JE. The health equity implementation framework: proposal and preliminary study of hepatitis $C$ virus treatment. Implement Sci. 2019;14(1):26.

5. Eslava-Schmalbach J, Garzón-Orjuela N, Elias V, Reveiz L, Tran N, Langlois EV. Conceptual framework of equity-focused implementation research for health programs (EquIR). International Journal for Equity in Health. 2019;18(1):80.

6. Damschroder LJ. Clarity out of chaos: Use of theory in implementation research. Psychiatry research. 2020;283:112461.

7. Damschroder LJ, Aron DC, Keith RE, Kirsh SR, Alexander JA, Lowery JC. Fostering implementation of health services research findings into practice: a consolidated framework for advancing implementation science. Implementation Science. 2009;4(1):50.

8. Goffman E. Stigma: Notes on the Management of Spoiled Identitiy. New York: Simon \& Schuster, Inc.; 1963.

9. Hatzenbuehler ML, Phelan JC, Link BG. Stigma as a fundamental cause of population health inequalities. American journal of public health. 2013;103(5):813-21.

10. Link BG, Phelan JC. Stigma and its public health implications. Lancet. 2006;367(9509):528-9.

11. Zickmund S, Ho EY, Masuda M, Ippolito L, LaBrecque DR. "They Treated Me Like a Leper": Stigmatization and the Quality of Life of Patients with Hepatitis C. J Gen Intern Med. 2003;18(10):835-44.

12. Marinho RT, Barreira DP. Hepatitis C. stigma and cure. World J Gastroenterol. 2013;19(40):6703-9.

13. Dowsett LE, Coward S, Lorenzetti DL, MacKean G, Clement F. Living with Hepatitis C Virus: A Systematic Review and Narrative Synthesis of Qualitative Literature. Can J Gastroenterol Hepatol. 2017;2017:3268650.

14. Taylor-Young P, Hildebrandt $E$. The multidimensional burden of hepatitis $C$ and its treatment: a case study. Gastroenterol Nurs. 2009;32(3):180-7.

15. Ly KN, Miniño AM, Liu SJ, Roberts H, Hughes EM, Ward JW, et al. Deaths Associated With Hepatitis C Virus Infection Among Residents in 50 States and the District of Columbia, 2016-2017. Clinical Infectious Diseases. 2019.

16. Ly KN, Hughes EM, Jiles RB, Holmberg SD. Rising Mortality Associated With Hepatitis C Virus in the United States, 2003-2013. Clin Infect Dis. 2016;62(10):1287-8.

17. Centers for Disease Control and Prevention. Surveillance for Viral Hepatitis - United States. 2017. 2017. 
18. Ghany MG, Morgan TR. Hepatitis CG. 2019 Update: American Association for the Study of Liver Diseases-Infectious Diseases Society of America Recommendations for Testing, Managing, and Treating Hepatitis C Virus Infection. Hepatology (Baltimore, Md). 2020;71(2):686-721.

19. Falade-Nwulia O, Suarez-Cuervo C, Nelson DR, Fried MW, Segal JB, Sulkowski MS. Oral Direct-Acting Agent Therapy for Hepatitis C Virus Infection: A Systematic Review. Ann Intern Med. 2017;166(9):637-48.

20. Patel SV, Jayaweera DT, Althoff KN, Eron JJ, Radtchenko J, Mills A, et al. Real-world efficacy of direct acting antiviral therapies in patients with HIV/HCV. PLOS ONE. 2020;15(2):e0228847.

21. McGlynn EA, Adams JL, Kramer J, Sahota AK, Silverberg MJ, Shenkman E, et al. Assessing the Safety of Direct-Acting Antiviral Agents for Hepatitis C. JAMA Netw Open. 2019;2(6):e194765-e.

22. Carrat F, Fontaine H, Dorival C, Simony M, Diallo A, Hezode $C$, et al. Clinical outcomes in patients with chronic hepatitis $\mathrm{C}$ after direct-acting antiviral treatment: a prospective cohort study. Lancet. 2019;393(10179):1453-64.

23. Butt AA, Yan P, Shaikh OS, Lo Re V 3rd, Abou-Samra AB, Sherman KE. Treatment of HCV reduces viral hepatitis-associated liver-related mortality in patients: An ERCHIVES study. J Hepatol. 2020.

24. Bashir MH, Fazili J, Madhoun MF, Kanagala R, Chen S, Nusrat S. Impact of sustained virologic response on short-term clinical outcomes in hepatitis C-related cirrhosis. Eur J Gastroenterol Hepatol. 2018;30(3):296-301.

25. Nahon P, Layese R, Bourcier V, Cagnot C, Marcellin P, Guyader D, et al. Incidence of Hepatocellular Carcinoma After Direct Antiviral Therapy for HCV in Patients With Cirrhosis Included in Surveillance Programs. Gastroenterology. 2018;155(5):1436-50.e6.

26. Kesen O, Kani HT, Yanartaş Ö, Aykut UE, Gök B, Gündüz F, et al. Evaluation of depression, anxiety and quality of life in hepatitis $C$ patients who treated with direct acting antiviral agents. Turk $\mathrm{J}$ Gastroenterol. 2019;30(9):801-6.

27. National Academies of Sciences, Engineering, and Medicine. Eliminating the Public Health Problem of Hepatitis B and C in the United States. Washington, DC: The National Academies Press; 2016. doi:10.17226/23407.

28. Gowda C, Lott S, Grigorian M, Carbonari DM, Saine ME, Trooskin S, et al. Absolute Insurer Denial of Direct-Acting Antiviral Therapy for Hepatitis C: A National Specialty Pharmacy Cohort Study. Open Forum Infectious Diseases. 2018;5(6).

29. Lo Re V, Gowda C, Urick PN, Halladay JT, Binkley A, Carbonari DM, et al. Disparities in Absolute Denial of Modern Hepatitis C Therapy by Type of Insurance. Clinical gastroenterology hepatology: the official clinical practice journal of the American Gastroenterological Association. 2016;14(7):103543.

30. Roberson JL, Lagasca AM, Kan VL. Comparison of the Hepatitis C Continua of Care Between Hepatitis C Virus/HIV Coinfected and Hepatitis C Virus Mono-Infected Patients in Two Treatment Eras During 2008-2015. AIDS Res Hum Retroviruses. 2018;34(2):148-55. 
31. Collins LF, Chan A, Zheng J, Chow S-C, Wilder JM, Muir AJ, et al. Direct-Acting Antivirals Improve Access to Care and Cure for Patients With HIV and Chronic HCV Infection. Open Forum Infectious Diseases. 2018;5(1):ofx264.

32. Jemal A, Fedewa SA. Recent Hepatitis C. Virus Testing Patterns Among Baby Boomers. Am J Prev Med. 2017;53(1):e31-e3.

33. Coyle C, Moorman AC, Bartholomew T, Klein G, Kwakwa H, Mehta SH, et al. The Hepatitis C Virus Care Continuum: Linkage to Hepatitis $C$ Virus Care and Treatment Among Patients at an Urban Health Network, Philadelphia, PA. Hepatology (Baltimore. Md). 2019;70(2):476-86.

34. Kanwal F, Kramer JR, El-Serag HB, Frayne S, Clark J, Cao Y, et al. Race and Gender Differences in the Use of Direct Acting Antiviral Agents for Hepatitis C Virus. Clin Infect Dis. 2016;63(3):291-9.

35. Marcus J, Hurley L, Chamberland S, Champsi J, Gittleman L, Korn D, et al. Racial/Ethnic and Socioeconomic Disparities in Initiation of Direct-Acting Antiviral Agents for Hepatitis $C$ Virus in an Insured Population. Open Forum Infectious Diseases. 2017;4(Suppl 1):198-S.

36. Marcus JL, Hurley LB, Chamberland S, Champsi JH, Gittleman LC, Korn DG, et al. Disparities in Initiation of Direct-Acting Antiviral Agents for Hepatitis $C$ Virus Infection in an Insured Population. Public Health Rep. 2018;133(4):452-60.

37. Wong RJ, Jain MK, Therapondos G, Shiffman ML, Kshirsagar O, Clark C, et al. Race/ethnicity and insurance status disparities in access to direct acting antivirals for hepatitis $\mathrm{C}$ virus treatment. Am J Gastroenterol. 2018;113(9):1329-38.

38. Perlman DC, Jordan AE. Using qualitative data, people's perceptions, and the science of decision making to inform policy and improve hepatitis $\mathrm{C}$ care for people who use drugs. Int J Drug Policy. 2015;26(2):217-9.

39. Nyblade L. Measuring HIV stigma: Existing knowledge and gaps. Psychology Health Medicine. 2006;11(3):335-45.

40. Loutfy MR, Logie $\mathrm{CH}$, Zhang Y, Blitz SL, Margolese SL, Tharao WE, et al. Gender and Ethnicity Differences in HIV-related Stigma Experienced by People Living with HIV in Ontario, Canada. PLoS ONE. 2012;7(12):e48168.

41. Sengupta S, Banks B, Jonas D, Miles MS, Smith GC. HIV interventions to reduce HIV/AIDS stigma: a systematic review. AIDS Behav. 2011;15(6):1075-87.

42. Lekas HM, Siegel K, Leider J. Felt and enacted stigma among HIV/HCV-coinfected adults: the impact of stigma layering. Qual Health Res. 2011;21(9):1205-19.

43. Paterson BL, Backmund M, Hirsch G, Yim C. The depiction of stigmatization in research about hepatitis C. Int J Drug Policy. 2007;18(5):364-73.

44. Chambers LA, Rueda S, Baker DN, Wilson MG, Deutsch R, Raeifar E, et al. Stigma, HIV and health: a qualitative synthesis. BMC Public Health. 2015;15:848.

45. Bowleg L. The Problem With the Phrase Women and Minorities: Intersectionality-an Important Theoretical Framework for Public Health. Am J Public Health. 2012;102(7):1267-73. 
46. Crenshaw K. Demarginalising the intersection of race and sex: A black feminist critique of antidiscrimination doctrine, feminist theory, and anti-racist politics. 1402011. p. 25-42.

47. Link BG, Phelan JC. Conceptualising stigma. 2001.

48. Jackson-Best F, Edwards N. Stigma and intersectionality: a systematic review of systematic reviews across HIV/AIDS, mental illness, and physical disability. BMC Public Health. 2018;18(1):919.

49. Sandelowski M, Barroso J, Voils Cl. Gender. Race/Ethnicity, and Social Class in Research Reports on Stigma in HIV-Positive Women. Health Care Women Int. 2009;30(4):273-88.

50. Turan JM, Elafros MA, Logie CH, Banik S, Turan B, Crockett KB, et al. Challenges and opportunities in examining and addressing intersectional stigma and health. BMC Med. 2019;17(1):7.

51. Philadelphia Fight. Philadelphia FIGHT Community Health Centers Annual Report 2018. Annual Report. Philadelphia: Philadelphia FIGHT; 2018.

52. 2017 Division of Disease Control (DDC). Annual Report. Annual Report. Philadelphia: Philadelphia Department of Public Health, Division of Disease Control; 2017.

53. University of Pennsylvania Health System (UPHS). 2016 COMMUNITY HEALTH NEEDS ASSESSMENT. Philadelpha, Pa2016.

54. Tong A, Sainsbury P, Craig J. Consolidated criteria for reporting qualitative research (COREQ): a 32item checklist for interviews and focus groups. Int J Qual Health Care. 2007;19(6):349-57.

55. Strauss AC. Juliet. Basics of Qualitative Research (3rd ed.): Techniques and Procedures for Developing Grounded Theory. Thousand Oaks, California2008. Available from: http://methods.sagepub.com/book/basics-of-qualitative-research.

56. Weiss RS. Learning from strangers: the art and method of qualitative interview studies: First Free Press paperback edition. New York : Free Press, 1995. (c)1994; 1995.

57. Group NMHSPTfAAC. Designing an Audio Computer-Assisted Self-Interview System in a Multisite Trial: A Brief Report. Journal of acquired immune deficiency syndromes. (1999). 2008;49(Suppl 1):S52-S8.

58. Saine ME, Moore TM, Szymczak JE, Bamford LP, Barg FK, Mitra N, et al. Validation of a modified Berger HIV stigma scale for use among patients with hepatitis $\mathrm{C}$ virus (HCV) infection. PLOS ONE. 2020;15(2):e0228471.

59. Berger BE, Ferrans CE, Lashley FR. Measuring stigma in people with HIV: psychometric assessment of the HIV stigma scale. Res Nurs Health. 2001;24(6):518-29.

60. Corbin J, Strauss A. Grounded theory research: Procedures, canons and evaluative criteria. Qualitative Sociology. 1990;13:3-21.

61. Glaser BG, Strauss AL. The discovery of grounded theory; strategies for qualitative research. Chicago,: Aldine Pub. Co.; 1967. x, 271 p. p.

62. Ly KN, Xing J, Klevens RM, Jiles RB, Ward JW, Holmberg SD. The Increasing Burden of Mortality From Viral Hepatitis in the United States Between 1999 and 2007. Ann Intern Med. 2012;156(4):271-8. 
63. Hunting G. Intersectionality-informed Qualitative Research: A Primer. San Fransisco: The Institute for Intersectionality Research \& Policy, SFU; 2014.

64. Miles MB, Huberman AM. Qualitative data analysis: an expanded sourcebook. 2nd ed. Thousand Oaks: Sage Publications; 1994. xiv, 338 p. p.

65. Butt G, Paterson BL, McGuinness LK. Living with the stigma of hepatitis C. West J Nurs Res. 2008;30(2):204-21. discussion 22-33.

66. Moore GA, Hawley DA, Bradley P. Hepatitis C: studying stigma. Gastroenterol Nurs. 2008;31(5):34652.

67. Habib SE, Adorjany LV. Hepatitis $C$ and injecting drug use: The realities of stigmatisation and discrimination. Health Education Journal. 2003;62(3):256-65.

68. Stewart BJ, Mikocka-Walus AA, Harley H, Andrews JM. Help-seeking and coping with the psychosocial burden of chronic hepatitis C: a qualitative study of patient, hepatologist, and counsellor perspectives. Int J Nurs Stud. 2012;49(5):560-9.

69. Treloar C, Rance J, Backmund M. Understanding Barriers to Hepatitis C Virus Care and Stigmatization From a Social Perspective. Clin Infect Dis. 2013;57(Supp 2):51-S5.

70. Rhodes T, Harris M, Martin A. Negotiating access to medical treatment and the making of patient citizenship: the case of hepatitis C treatment. Sociol Health IIIn. 2013;35(7):1023-44.

71. Jauffret-Roustide M, Cohen J, Poisot-Martin I. Distributive sharing among HIV-HCV co-infected injecting drug users: the preventive role of trust in one's physician. 2012. p. 232-8.

72. Henry B. DRUG, PRICING \& CHALLENGES TO HEPATITIS C TREATMENT ACCESS. J Health Biomed Law. 2018;14:265-83.

73. Tenner L, Melhado TV, Bobadilla R, Turner BJ, Morgan R. The Cost of Cure: Barriers to Access for Hepatitis C Virus Treatment in South Texas. Journal of Oncology Practice. 2019;15(2):61-3.

74. Trooskin SB, Reynolds H, Kostman JR. Access to Costly New Hepatitis C Drugs: Medicine, Money, and Advocacy. Clin Infect Dis. 2015.

75. Canary LA, Klevens RM, Holmberg SD. Limited Access to New Hepatitis C Virus Treatment Under State Medicaid Programs. Ann Intern Med. 2015;163(3):226-8.

76. Parker R, Aggleton P. HIV and AIDS-related stigma and discrimination: a conceptual framework and implications for action. Soc Sci Med. 2003;57(1):13-24.

77. Martinez RG, Lewis CC, Weiner BJ. Instrumentation issues in implementation science. Implementation Science. 2014;9(1):118.

78. Zickmund S, Hillis SL, Barnett MJ, Ippolito L, LaBrecque DR. Hepatitis C virus-infected patients report communication problems with physicians. Hepatology. 2004;39(4):999-1007.

79. Wolfe D, Luhmann N, Harris M, Momenghalibaf A, Albers E, Byrne J, et al. Human rights and access to hepatitis C treatment for people who inject drugs. Int J Drug Policy. 2015;26(11):1072-80.

80. Hacking I. Making Up People. In: Heller TC, Brooke-Rose C, editors. Reconstructing individualism: autonomy, individuality, and the self in Western thought. Stanford, Calif.: Stanford University Press; 
1986. p. xiv, 365 p.

\section{Tables}

Page 18/24 
Table 1. Characteristics of participants with qualitative data.

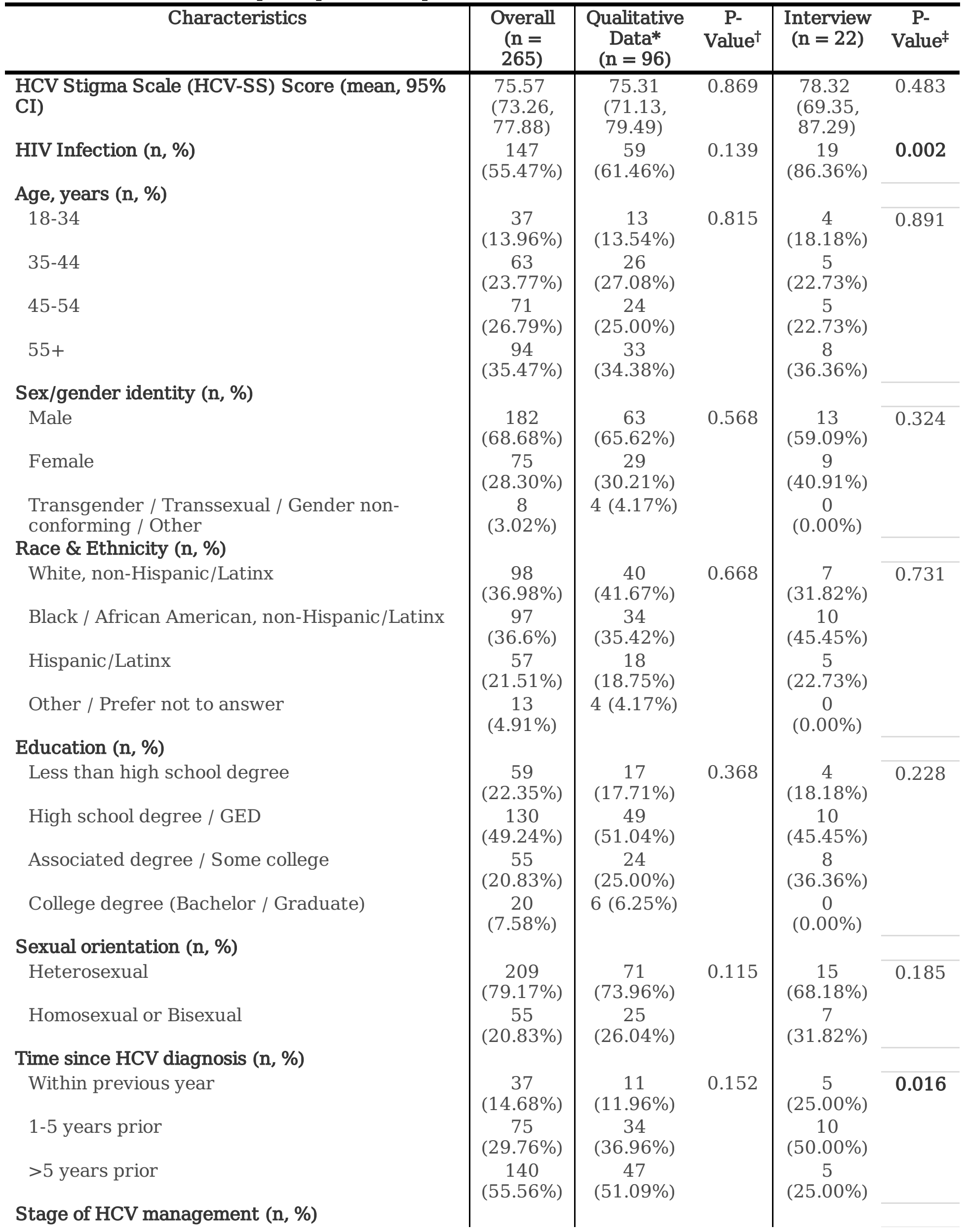


Spontaneously cleared; Diagnosed, Untreated; or Previously treated, Not cured

Currently being treated

Treated, Cured

\section{HCV treatment with PEGylated interferon (n, \%)}

History of injection drug use (n, \%)

\begin{tabular}{|c|cc|cc}
78 & 26 & 0.269 & 8 & 0.694 \\
$(29.43 \%)$ & $(27.08 \%)$ & & $(36.36 \%)$ & \\
77 & 24 & & 5 & \\
$(29.06 \%)$ & $(25.00 \%)$ & & $(22.73 \%)$ & \\
110 & 46 & & 9 & \\
$(41.51 \%)$ & $(47.92 \%)$ & & $(40.91 \%)$ & \\
53 & 19 & 0.949 & 5 & 0.781 \\
$(20.00 \%)$ & $(19.79 \%)$ & & $(22.73 \%)$ & \\
196 & 71 & 0.999 & 17 & 0.805 \\
$(73.96 \%)$ & $(73.96 \%)$ & & $(77.27 \%)$ & \\
\hline
\end{tabular}

Abbreviations: $\mathrm{HCV}=$ Hepatitis $\mathrm{C}$ Virus, $\mathrm{SD}=$ Standard deviation; HIV=Human Immunodeficiency Virus P-values $<0.05$ are bolded

*Qualitative data includes participants with interview and/or free-response data

${ }^{\dagger} \mathrm{P}$-value for characteristics of participants with any qualitative data (interview and/or free response), compared to study participants with no qualitative data

${ }^{\ddagger}$ P-value for characteristics of interview participants compared to study participants who were not interviewed

Table 1 Legend: Characteristics are presented overall, for interview participants, and for participants with any qualitative data (interview and/or free response). P-values compare characteristics of study pool to interview participants and participants with any qualitative data.

Table 2. HCV-SS Stigma Scores.

\begin{tabular}{|l|c|c|c|c}
\hline \multicolumn{1}{|c|}{ Race/Ethnicity } & $\begin{array}{c}\text { Endorsed Stigma } \\
\mathbf{( \% )}\end{array}$ & $\begin{array}{c}\text { P- } \\
\text { Value* }^{*}\end{array}$ & $\begin{array}{c}\text { HCV-SS Score } \\
\text { Adjusted Mean (95\% } \\
\text { CI) }\end{array}$ & $\begin{array}{c}\text { P- } \\
\text { Value }^{\dagger}\end{array}$ \\
\hline White, non-Hispanic/Latinx & $92.86 \%$ & & $74.28(70.51,78.05)$ & - \\
\hline $\begin{array}{l}\text { Black/African American, non- } \\
\text { Hispanic/Latinx }\end{array}$ & $97.94 \%$ & 0.170 & $74.33(70.54,78.12)$ & 0.984 \\
\hline Hispanix/Latinx & $98.25 \%$ & 0.259 & $81.39(76.44,86.33)$ & $\mathbf{0 . 0 2 5}$ \\
\hline Other & $84.62 \%$ & 0.284 & $69.08(58.72,79.43)$ & 0.354 \\
\hline
\end{tabular}

Abbreviations: HCV=Hepatitis C Virus, HCV-SS=HCV Stigma Scale; CI=Confidence interval P-values $<0.05$ are bolded

*P-values compare proportion of participants who endorsed at least one stigma item for each subgroup to the White, non-Hispanic/Latinix group

${ }^{\dagger} \mathrm{P}$-values compare mean stigma score for each subgroup to the White, non-Hispanic/Latinix group

Table 2 Legend: Proportion of participants who endorsed any stigma item and HCV-SS scores are presented by race/ethnicity. P-values compare mean HCV-SS score for each group to White, nonHispanic/Latinx participants. 


\section{\begin{tabular}{l|l}
\hline Factor \& & Exemplar Quote \\
\hline
\end{tabular} \\ Theme}

Patients

Factors

Feelings of dirtiness

Shame

\section{Provider \\ Factors}

Source of

support

Negative

treatment by

non-specialty

Providers
"I was thinking to myself, "Well, I had it but now I'm cured and I don't have it." But I still feel like I was contaminated. I still have that feeling. I guess, it's from knowing that I once had it."

(Hispanic; HCV-SS Score, 103)

"I just felt like I was dirty. Like I'll never be right again."

(White, non-Hispanic; HCV-SS Score, 97)

"I don't advertise. And like I said, not even so much all the time because of just being a disease but because of how I got it. I'm embarrassed that I became a heroin addict, you know?"

(White, non-Hispanic; HCV-SS Score 75)

"When I found out I had it, I wasn't afraid to tell anyone. People need to know so they can get help. A lot of people don't know they have it. They see it on tv and won't go inquire about it. I have never been ashamed of it. I was never a user; I got mine through blood transfusions."

(Black, non-Hispanic; HCV-SS Score, 52)

"When I found out I had it and I had to come over here, I thought people would look at me differently, but everyone in this office, Dr. [X], it felt like a family."

(Black, non-Hispanic; HCV-SS Score, 83)

"The only support that I got, the doctor. I mean, the whole team, because I think they are the only people who really know about my situation. I don't let nobody know what's really going on with me. So they are really my life support."

(Hispanic; HCV-SS Score 75)

"I kept going to [clinics] and other places that are similar to this place and I was getting denied. I didn't understand why...it was like, almost like when you are a child and you get scolded. That's what it felt like. Like I was being scolded for doing wrong."

(Hispanic; HCV-SS Score 103)

"I have found that I have been treated worse by some of the doctors I have seen. Coming from a person educated in health this has been the hardest thing to come to terms with."

(White, non-Hispanic; HCV-SS Score 96)

Bias \& structural racism
"She's a $A A A+$. She's a true doctor. She's not prejudice or nothing. She don't care what race you is, she is willing to sit there, talk to you, and help you to the best of her ability because that's what she went to school for."

(Black, non-Hispanic; HCV-SS Score, 78)

"Dr. [X] is a wonderful doctor, but she don't see what you get. People discriminate against you and you're not treated fairly once you get to the emergency room or you want to check in...It's discouraging...People don't want to be around you, because if they cut they gloves or cut they selves helping you, they could get it too."

(Black, non-Hispanic; HCV-SS Score, 90)

"Well, I grew up in that era. I knew what it was like... There are things I see to this day. Some of them have given up their sheets for white jackets. There's still a lot of prejudice." 
Trust

\section{Other}

Recipients

Treatment by

family \&

friends

Disclosure

experiences

Shame \& social distancing
"Many of my close friends and relatives did not treat me any differently once they knew that I was infected with Hep C."

(White, non-Hispanic; HCV-SS Score 59)

"My parents always talked about people with sickness like Hep C or HIV. My parents always talked about people doing drugs and all that stuff. So when I found out that I had Hep C, I felt like my parents were there and they were just looking at me in a way they felt ashamed of me and they felt embarrassed of me. And, I just felt like trash."

(Hispanic; HCV-SS Score, 90)

"See, in the black community, people have stigmas and they judgmental. So this what I don't need to do, telling them I got HIV and hepatitis C."

(Black, non-Hispanic; HCV-SS Score, 90)

"I don't tell anyone what have...I go here, go to the doctor, go home...I don't tell people in my neighborhood. I go to church and read the bible, but I keep to myself."

(Hispanic; HCV-SS Score, 78)

"When people find out you have hep c, they look at you different. They distance themselves from you, don't want to associate with you because they don't want to catch it."

(Hispanic; HCV-SS Score, 86)

"I think that the racist and vile way people treat you because you are sick is disgusting. Just because I'm ill doesn't make me a bad or slimy person, I deserve love like everyone else"

(Black, non-Hispanic; HCV-SS score, 119)

\section{Characteristics of Innovation}

Media

Portrayals of

DAAs

"I look at the Harvoni commercials, there's as many whites as there are blacks. And the commercials are good because they use well-educated, well employed people to do them, you know, which lets you know that it's not an impoverished disease. It's not a black disease, it's not a white disease. It's not gay. It's not a disease from drug addicts. I mean, even though in these ways, it can be passed, but this is not the cause and we're also learning segregating us as people is not the cure."

(Black, non-Hispanic; HCV-SS Score, 78)

"They advertised on TV every day - Harvoni, it heals you."

(Black, non-Hispanic; HCV-SS Score, 59)

High cost of drugs

Insurer denials of treatment
"Everything is business. And I know, because every time I go to the pharmacy, I can see the price over every medication they give me. And every kind of medication for our disease is really expensive. And they're not going to lose a lot of big income."

(White, non-Hispanic; HCV-SS Score 75)

"People with Hep C tend to be treated as addicts and don't get treated because the insurance believes they will use again and simply waste their money, which isn't always the case." 
"I feel like they didn't want to pour a lot of money into you either, do a lot of tests and something like that. Because, for what if you're not taking care of yourself and you just going to go out and die? That's like a waste of time for them and a waste of money and resources. That's how I feel. That's exactly how I feel like they look at you."

(Black, non-Hispanic; HCV-SS Score, 90)

\section{Figures}

1 .

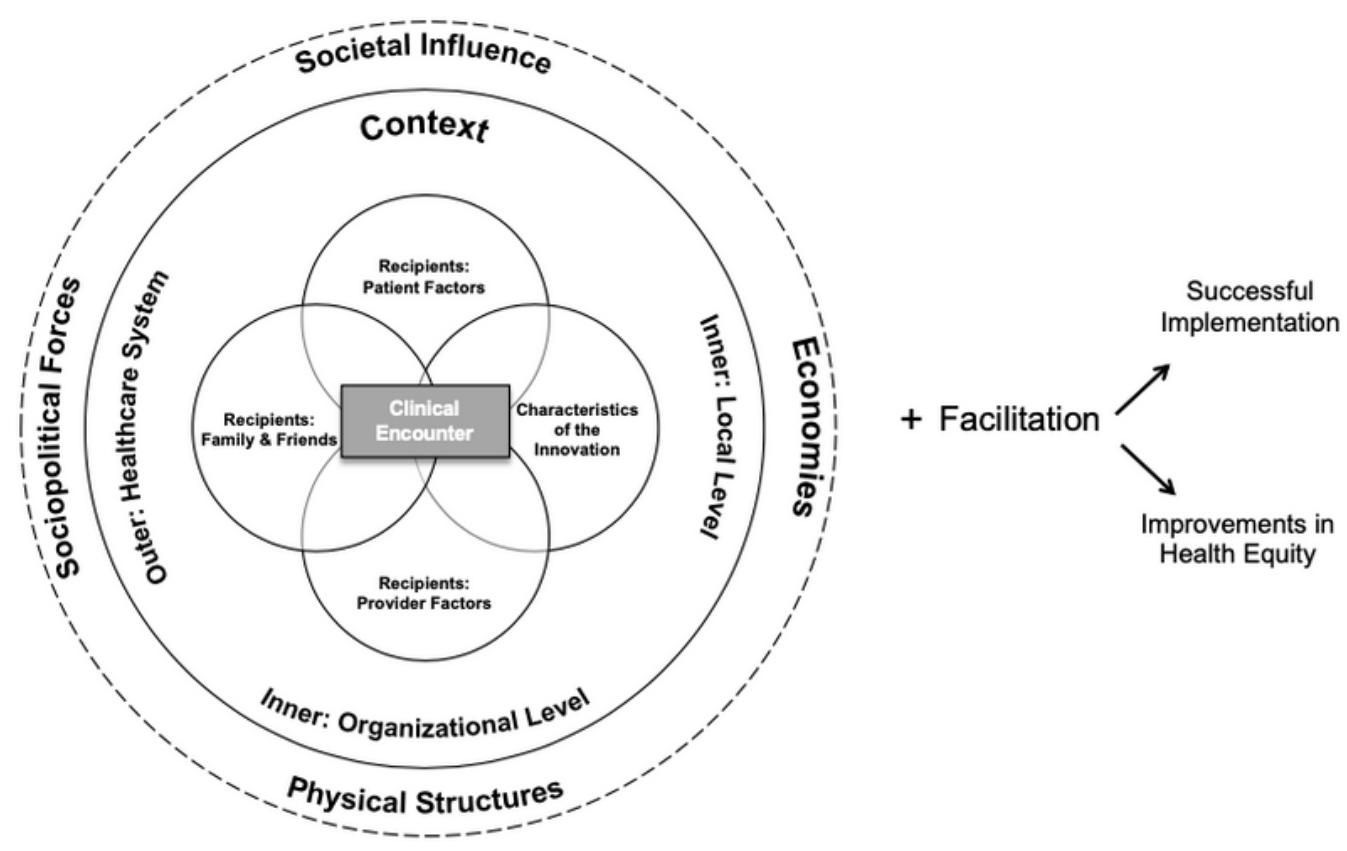

1b.

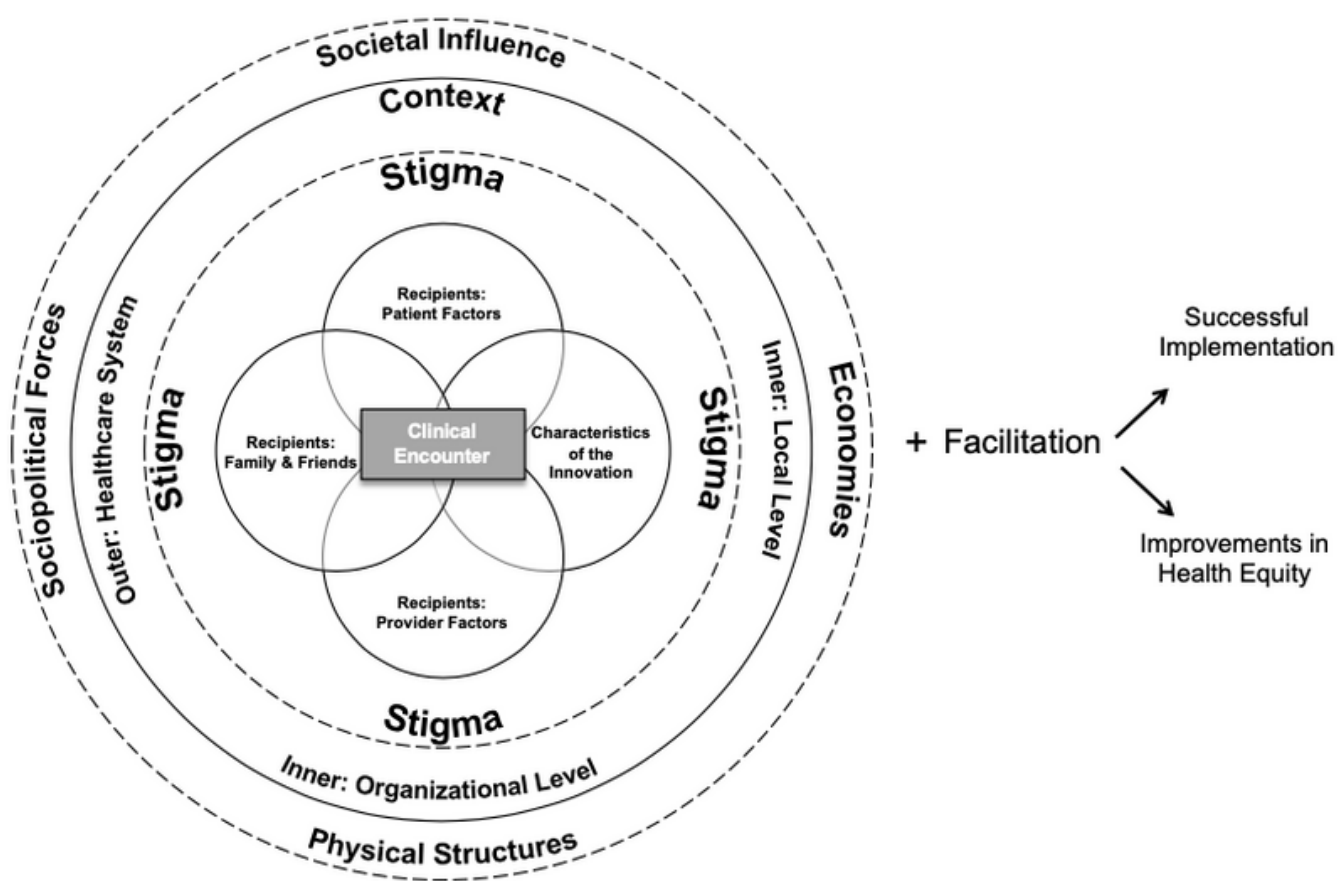




\section{Figure 1}

Influence of Stigma within The Health Equity Implementation Framework. Fig 1a is The Health Equity Implementation Framework developed by Woodward et. al (2019). Within this framework, the clinical encounter is an interaction between recipients (patients, providers, and friends and family of who provide social support to the patient) and the innovation itself. Fig $1 \mathrm{~b}$ revises The Health Equity Implementation Framework to incorporate stigma as a mechanism through which societal influence impacts the clinical encounter. The dashed line encompassing societal influence and stigma symbolizes this translational power of stigma between societal influence and clinical encounters. By incorporating stigma into the Health Equity Implementation Framework, we can evaluate the impact on implementation and health disparities.

\section{Supplementary Files}

This is a list of supplementary files associated with this preprint. Click to download.

- STIGMACOREQChecklistFINAL071920.pdf 